\title{
LOS MEMES COMO ARMA ELECTORAL ${ }^{1}$
}

Fernando Esquivel Lozano ${ }^{2}$

\section{Introducción}

El uso de las nuevas tecnologías en las contiendas electorales ha derivado en la utilización de nuevas herramientas para llevar a cabo el posicionamiento de los partidos políticos y de los candidatos, con el fin de lograr alcanzar el objetivo final, que es el de ganar la elección.

Las campañas políticas que anteriormente se desarrollaban "en tierra", con los recorridos que hacían los candidatos por el territorio electoral que aspiraban representar o gobernar, ahora se efectúan también en el ciberespacio, donde se libran cruentas batallas tratando de ganar o restar votos, según sea necesario.

De esas nuevas herramientas, la que ha registrado un enorme potencial son los llamados "memes", esa unidad de información, generalmente gráfica, que sirve para presentar de manera cómica un suceso o acontecimiento de la vida cotidiana. Los electores no solamente los consumen en gran medida, sino que generan sus propios memes, propiciando con esto el debate y la interacción política que en tiempos no muy lejanos ni siquiera existían. Hay una riqueza en la comunicación política que anteriormente no se tenia, pero que también representa un serio peligro para los distintos actores electorales.

\footnotetext{
${ }^{1}$ Esta investigación se presentó en el congreso Wapor 2016, en la Facultad de Ciencias Políticas y Administración Pública de la UANL, en Monterrey, México, en octubre de 2016.

${ }^{2}$ Catedrático e investigador en la Facultad de Ciencias de la Comunicación de la Universidad Autónoma de Nuevo León (UANL), donde fue Decano; profesor invitado en la Universidad Autónoma de Barcelona (UAB).
} 
Los memes han sido utilizados en mayor medida para atacar, denostar y ridiculizar a los contrarios, lo que ha propiciado un incremento notable en la proliferación de las campañas "negras" o negativas.

Ante la falta de una legislación adecuada que incluya la comunicación política que se desarrolla en Internet, la guerra sucia es el pan de cada día en las contiendas electorales de cualquier nivel, lo que, si bien incrementa el flujo de comunicación, también sirve para generar desaliento y desconfianza entre los electores. La participación ciudadana puede disminuir si llega a pesar más la influencia negativa de los mensajes que se reciben.

En el estado de Nuevo León, en el norte de México, se desarrollaron elecciones locales en el año 2015, con un resultado inédito en la historia electoral del país: un candidato sin partido alcanzó la gobernación mediante un modelo de comunicación política que incluyó en gran medida el uso de las Tecnologias de la Información y Comunicación (TIC), concretamente, las Redes Sociales.

Los memes estuvieron presentes y fueron utilizados por todos los contendientes en un nivel nunca visto, de tal forma que minimizaron los mensajes políticos "serios", ya que los electores estaban más pendientes de la aparición de los memes que de las propuestas y programas de trabajo de los candidatos.

Es por eso que en esta investigación se aborda el tema de los memes, desde su utilización a su posible influencia en los resultados obtenidos en dicha elección.

El objetivo principal fue analizar la utilización de memes por todos los candidatos y partidos y el papel que estos jugaron en las preferencias electorales de los ciudadanos.

\section{¿De dónde surgen los memes?}

El origen de los memes viene del estudio de la evolución de las especies desde la perspectiva de los genes y fue Richard Dawkins (1993), en su libro El gen egoísta, el prime- 
ro que acuñó dicho término; conviene aclarar, sin embargo, que esto nada tiene que ver con la acepción que utilizamos ahora de esta herramienta tecnológica.

Si bien la memética trata sobre el estudio formal de los memes, es importante señalar que, desde la perspectiva sociológica, en realidad estamos hablando de una transferencia de información cultural.

El meme, a diferencia de los genes que transmiten la información de manera generacional, no está sometido a una evolución, sino más bien a una competencia que hace que unos desplacen a otros, tratando de acaparar la atención de los internautas y consumidores de esas unidades de información. Así, Dawkins (1993) definió meme como la unidad mínima de información cultural transmisible de una mente a otra, así como de una generación a otra, mediante replicación y transmisión.

A efectos de esta investigación, los memes son un fenómeno de Internet que se encarga de presentar una idea, concepto, situación o expresión, a través de un medio virtual que puede ser una caricatura, texto, video, imagen 0 contenido multimedia, para presentar de manera humorística situaciones de la vida diaria (Jaén, 2012).

\section{Sus características y tipos}

Los memes poseen características específicas que han hecho posible que se convirtieran en una moda muy extendida en todos los ámbitos de la vida cultural de los individuos, aunque es en la política y en el deporte donde su uso se ha generalizado.

Haciendo una analogía con lo expresado por Maynou (2012), podemos establecer que los memes representan:

a. Viralidad. Se propaga y transmite como un virus dentro de un organismo. Es contagioso.

b. Longevidad. Debe perdurar, a diferencia de otros, para ser reconocido. 
c. Fidelidad. Respeta el mensaje que le dio origen, aunque este sea presentado en diferente manera o formato.

Los memes pueden ser de diferentes tipos, tales como videos, imágenes, texto, Internet Face o Rage Comics, siendo de todos estos las imágenes y los videos los más utilizados hasta ahora.

El formato de texto, si bien no ha sido utilizado tanto a lo largo de la historia de los memes, últimamente ha adquirido notoriedad con la utilización de los hashtags provenientes del sitio de microblogging Twitter.

Con mucha menos utilización se encuentra Internet $\mathrm{Fa}-$ $c e$, que son imágenes de rostros realizadas con el programa de dibujo Paint y que fueron popularizadas por el sitio 4chan.

Esta clasificación no deja de ser inicial, ya que, como se sabe, en Internet cada vez surgen nuevos conceptos y herramientas que también pueden ser utilizados para crear todo tipo de memes.

\section{Contexto}

Las elecciones en Nuevo León, en las que se inscribieron inicialmente 10 candidatos, se desarrollaron del 6 de marzo al 7 de junio de 2105, siendo este último día la votación. Los resultados oficiales que informó la Comisión Estatal Electoral fueron los siguientes:

Jaime Rodríguez Calderón, alias el Bronco, candidato independiente, 48.824 \% (1, 020,552 votos); Ivonne Álvarez García, candidata de Alianza por tu Seguridad (PRI, Partido Verde, Nueva Alianza y Partido Demócrata), 23.855 \% (498.644 votos); Felipe de Jesús Cantú Rodríguez, Partido Acción Nacional, 22.320 \% (466.543 votos).

Ninguno de los otros cinco candidatos (dos renunciaron a la candidatura durante la campaña y se unieron al candidato independiente, siendo el caso más notorio el de Fernando Elizondo Barragán) alcanzó un punto porcentual de los votos emitidos por el $58.7 \%$ de los 3.560.457 ciudada- 
nos en lista nominal. El voto nulo fue del 2,153 \%, con un total de 45,012 votos anulados.

\section{Metodología}

Esta investigación, de tipo descriptivo, se centró en la revisión de los memes publicados en Internet durante la campaña electoral que se desarrolló del 6 de marzo al 6 de junio de 2015, considerando a todos los candidatos inscritos. Como muestra se consideraron los memes encontrados en el último mes de la contienda política (del 6 de mayo al 6 de junio), por considerarse que fue el periodo más intenso en la emisión de mensajes y, además, los candidatos que se retiraron durante la campaña ya no aparecían como tales.

No se incluyó el día de la votación (7 de junio) ni los días posteriores, para no contaminar la muestra y poder revisar libremente la posible influencia de los memes en los resultados electorales.

Para ubicar los memes publicados se utilizó la herramienta de Google Imágenes mediante el navegador Chrome, con los siguientes criterios:

a. Palabras clave: memes - elecciones - gobernador Nuevo León - 2015

b. Tamaño: cualquier tamaño

c. Color: cualquier color

d. Tipo: cualquier tipo

e. Fecha: del 6 de mayo de 2015 al 6 de junio de 2015

f. Derechos de uso: sin filtrar por licencia

Aunque se inició la contienda electoral con diez candidatos y dos de ellos renunciaron a favor del posterior ganador, la investigación se centró en los tres aspirantes de mayor penetración en el electorado: Ivonne Álvarez, de Alianza Por tu seguridad; Felipe de Jesús Cantú, del PAN y Jaime Rodríguez Calderón, candidato independiente.

Además, se incluyeron los memes relativos al gobernador del Estado, Rodrigo Medina, cuyo origen político es el 
PRI, por considerarse que fue parte de la campaña electoral, ya que su mandato fue sumamente cuestionado y muy ligado a la candidata de su partido.

Cabe mencionar que no se incluyó en esta investigación el objetivo de indagar el origen de los memes, es decir, quién o quiénes los emitieron, sino simplemente contabilizar y describir los que fueron encontrados.

\section{Análisis de resultados}

Los resultados encontrados en esta investigación fueron los siguientes:

Durante el periodo analizado se contabilizó un total de 43 imágenes tipo memes para los tres candidatos que encabezaban las encuestas y el gobernador priista Rodrigo Medina.

Asimismo, se encontró un total de 20 videos convertidos en memes, de los tres contendientes y el gobernante actual.

De las otras tipologías de memes (Texto, Internet Face o Rage Comics) no se encontraron resultados, por lo que no fueron tomados en cuenta en la base de datos y elaboración de las gráficas.

\section{Imágenes}

De las 43 imágenes encontradas a través del buscador Google Imágenes, la mayor cantidad correspondió al candidato independiente y ganador de la contienda, Jaime Rodríguez Calderón, con un total de 22, quedando en segundo lugar la candidata de Alianza por tu seguridad, Ivonne Álvarez, con 12. El tercer lugar fue para el gobernador Rodrigo Medina, mcon 8, y el cuarto y último lugar para Felipe de Jesús Cantú del Pan, con solo 1 meme. En el cuadro a continuación se presenta esta información así como el carácter -positivo, negativo o neutral- de los memes correspondientes a cada uno de los candidatos. 
Cuadro 1

Memes de imágenes para candidatos y gobernador

\begin{tabular}{|l|c|c|c|c|}
\hline & $\begin{array}{c}\text { Total de memes } \\
\text { por candidato }\end{array}$ & A favor & En contra & Neutral \\
\hline Jaime Rodriguez Calderón & 22 & 17 & 4 & 1 \\
\hline Ivonne Álvarez & 12 & 0 & 12 & 0 \\
\hline Rodrigo Medina & 8 & 0 & 8 & 0 \\
\hline Felipe de Jesús Cantú & 1 & 0 & 1 & 0 \\
\hline Total & 43 & & & \\
\hline
\end{tabular}

De los 22 memes que le correspondieron al candidato independiente Jaime Rodríguez Calderón, 17 de ellos fueron favorables, ya que se enaltecía su figura o se enviaba un mensaje positivo de su candidatura.

La carga positiva de los mensajes enfatizaba en la necesidad de un cambio de aires políticos, la valentía del candidato y sus cualidades para provocar un cambio de rumbo en la política estatal, así como presentarlo como el único que realmente podría acabar con la corrupción y la impunidad y llevar a la cárcel a los malos gobernantes.

Cuatro memes se consideraron negativos debido a que se le criticaba y uno más se consideró como un meme neutral, puesto que el contenido del mensaje era meramente informativo sin denotar una carga positiva o negativa para el candidato.

Por lo que toca a la candidata de Alianza por tu Seguridad, Ivonne Álvarez, de los 12 memes que registró, exactamente los 12 fueron considerados en contra, dado que se ridiculizaba su candidatura, se minimizaban sus cualidades o posibilidades de triunfo, se la relacionaba con conceptos de carga negativa como la corrupción, el burocratismo y el PRI o bien se la mencionaba como cómplice del gobernador Rodrigo Medina o como posible encubridora de los supuestos malos manejos del gobernante de turno. No se encontraron memes a favor ni neutrales. 
Foto 1

Memes de Jaime Rodríguez Calderón
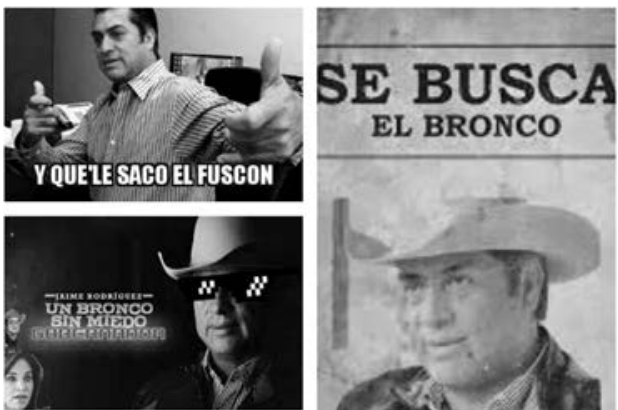

EL BRONCO

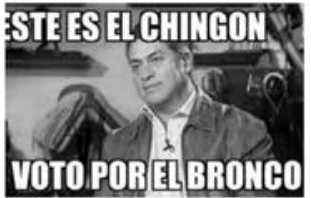

AIME RODRIGUEZ CALDEROI

'ARA DARLE MI FIRM,

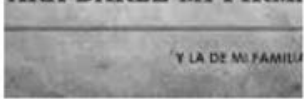

Foto 2

Memes de Ivonne Álvarez
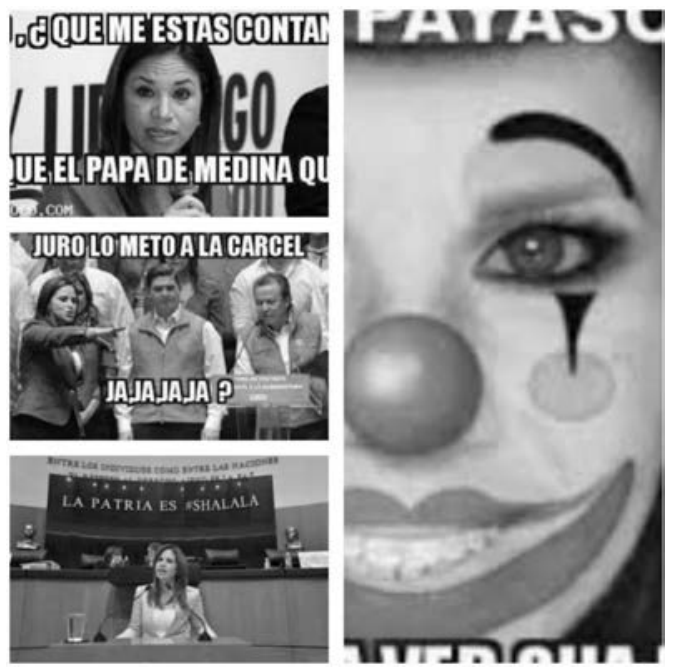
En esa misma línea se pueden considerar los 8 memes relativos al gobernador Rodrigo Medina, ya que los 8 fueron considerados en contra y no se registró ninguno a favor o neutral. Se le acusaba de apoyar la candidatura de Ivonne Álvarez para que le sirviera de "tapadera" al terminar su gobierno, de ser un político corrupto, de permitir que su padre tomase decisiones de gobierno para favorecer sus intereses económicos y de fomentar el enriquecimiento de su grupo político, entre otras cosas.

Algunos de los memes rescatados dan cuenta de esto:

Foto 3

Memes del Gobernador Rodrigo Medina
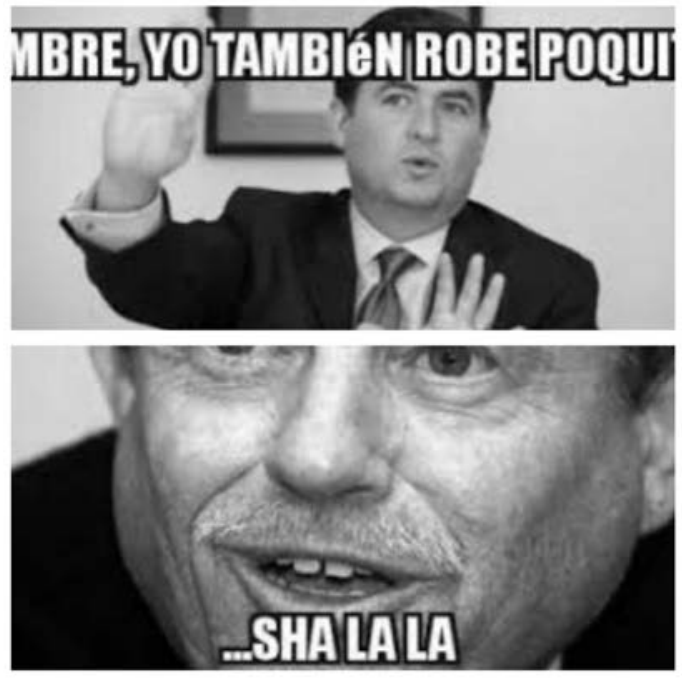

El que no tuvo gran participación fue el candidato del PAN, Felipe de Jesús Cantú, ya que solamente fue incluido en un solo meme, en el que se veía su fotografía con una gráfica de caída o de pérdida, tratando de emular un desplome en su candidatura y en sus posibilidades de ganar la contienda. No recibió ningún meme a su favor y tampoco hubo neutrales. 


\section{Foto 4}

Meme de Felipe de Jesús Cantú

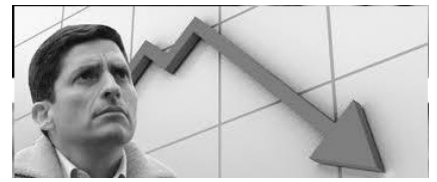

\section{Videos}

En lo que respecta a los videos, se encontró un total de 20, acaparados casi en su totalidad por el candidato independiente y posterior ganador de la contienda, Jaime Rodríguez Calderón, con un total de 17. Los 3 restantes memes fueron para la candidata de la Alianza por tu Seguridad, Ivonne Álvarez, mientras que el candidato del PAN, Felipe de Jesús Cantú, no apareció en ninguno, al igual que el gobernador Rodrigo Medina.

En el cuadro a continuación se presenta esta información así como el carácter -positivo, negativo o neutral- de los memes correspondientes a cada uno de los candidatos.

\section{Cuadro 2}

Memes de videos para candidatos y gobernador

\begin{tabular}{|l|c|c|c|c|}
\hline & $\begin{array}{c}\text { Total de memes } \\
\text { por candidato }\end{array}$ & A favor & En contra & Neutral \\
\hline Jaime Rodríguez Calderón & 17 & 17 & 0 & 0 \\
\hline Ivonne Álvarez & 3 & 0 & 3 & 0 \\
\hline Felipe de Jesús Cantú & 0 & 0 & 0 & 0 \\
\hline Rodrigo Medina & 0 & 0 & 0 & 0 \\
\hline Total & 20 & & & \\
\hline
\end{tabular}

De los 17 videomemes que correspondieron al ahora gobernador del estado de Nuevo León, Jaime Rodríguez Calderón, todos fueron considerados a su favor, debido a que la carga del mensaje siempre fue positiva, en el mismo tenor de las imágenes, es decir, maximizando su candidatura, sus cualidades, sus posibilidades de triunfo, sus logros en sus puestos políticos anteriores, así como en la posibilidad de que se 
convirtiese en el primer gobernador en la historia de México en llegar al poder sin el respaldo de un partido político. Ninguno de los videos presentó contenido negativo, ni neutral.

Esto no ocurrió con la candidata de la Alianza por tu Seguridad, Ivonne Álvarez, pues los tres videomemes que la mencionaban contenían una carga negativa. Se destacaba su falta de preparación, su juventud o inexperiencia, su pasado como conductora de un programa de televisión de corte muy popular y su relación con la central obrera CTM y se destacaban imágenes de su despedida de soltera y de una expresión (sha la la) que utilizó en una conversación telefónica para justificar unos faltantes financieros en su administración como alcaldesa del municipio de Guadalupe.

No registró ningún video a su favor, ni siquiera alguno neutral, convirtiéndose así en la candidata más atacada tanto en imágenes como en videos.

Como se mencionó al principio de este apartado, el otro candidato y el gobernador de turno no aparecieron en ningún video.

Foto 5

Videos
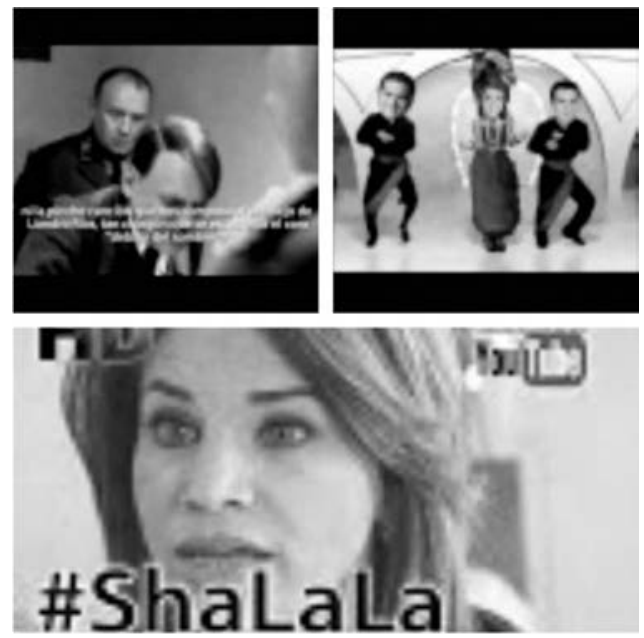


\section{Conclusiones y recomendaciones}

La elección por la gobernación del estado de Nuevo León en 2015 representó un parteaguas en la política nacional y podríamos decir que hasta internacional, por la trascendencia de que por primera vez un candidato sin partido alcanzara la gobernación de un estado mexicano, tras décadas de dominio partidista.

El uso de las Tecnologías de la Información y Comunicación (TIC) se convirtió en un recurso estratégico en la campaña electoral, siendo una de las armas más utilizadas por los distintos candidatos a la gobernación de Nuevo León. Esto fue provocado en parte por la posibilidad de reducción en el gasto de las campañas, pero sobre todo porque es un campo libre que todavía no es alcanzado por la legislación electoral y, por lo tanto, se pueden utilizar tanto para posicionarse como para atacar a los contrarios, sin dejar huella y mucho menos sufrir las consecuencias legales.

Cada vez se enfatiza más este uso de las nuevas tecnologías en la comunicación política y se espera que en el futuro este fenómeno se agudice; sin embargo, la llegada de nuevas herramientas como los memes ha sido un detonante, debido a que se trata de un recurso de toque sarcástico y humorístico que fácilmente atrapa al elector, de ahí su gran utilización.

En esta investigación se cumplió con el objetivo de analizar los mensajes tipo memes que fueron emitidos en el último tramo de la contienda electoral, buscando demostrar su uso como parte de la guerra sucia a la que recurren cada vez más los candidatos y los partidos políticos sin que las autoridades electorales puedan hacer nada por detenerla.

La mayoría de los memes emitidos, tanto en imágenes como en videos, fueron de carga negativa, lo que de alguna manera confirma que las campañas negras llegaron para quedarse, pero que ahora se refuerzan de manera increíble con la posibilidad de emitir mensajes de ataque a través de las Redes Sociales. 
Cabe destacar que el candidato ganador ha sido reconocido, antes y después de la contienda electoral, por el uso intensivo que hizo de dichas redes. Y en esta investigación queda demostrado que fue él precisamente el que más atención recibió en los mensajes políticos emitidos.

Como se mencionó en la metodología, no era objetivo de esta investigación determinar quién o quiénes fueron los autores de la emisión de los mensajes, por lo que se consideró esto como una limitación, al no poder contar con la suficiente información para dilucidar si los memes fueron creados y difundidos por los equipos de campaña o por propia iniciativa de los electores. Es por eso que se recomienda que se profundice en la investigación y en la legislación de la utilización de los memes como arma electoral, puesto que en futuras contiendas políticas su uso puede resultar de una gran influencia en las decisiones que tomen los electores. Sobre todo en las campañas negativas, que antes que buscar un buen posicionamiento de los candidatos lo que hacen es desprestigiar, difamar, denostar y calumniar a los opositores, lo que generalmente redunda en un desaliento de los ciudadanos para participar en las elecciones, con el grave peligro que esto representa para la sociedad en su conjunto.

\section{Referencias}

Blackmore, S. (2000) La máquina de los memes. Barcelona: Paidós, Ibérica.

Capanna, P. (2010) "Memes: los genes del pensamiento. Formación y Consultoría para Organizaciones". Recuperado de: http:// www.neuronilla.com/documentate/articulos/55-creatividaddefinicionreflexion-e-investigaci/632-memes-los-genes-delpensamiento-pablocapanna.html.

Cortés Morató, J. (s.f.) "¿Qué son los memes? Introducción general a la teoría de memes". Recuperado de: http://biblioweb. sindominio.net/memetica/memes.html. 
Dafonte Gómez, A. (s.f) "Aproximación teórica al concepto de viralidad desde el punto de vista de la comunicación. Aplicación y repercusiones en los contenidos publicitarios audiovisuales". Recuperado de: http://www.foro2014.com/wpcontent/ uploads/2014/02/43.-Dafonte-G\%C3\%B3mez.pdf.

Dawkins, R. (1993) El gen egoísta: Las bases biológicas de nuestra conducta. Traducción de Juana Robles Suárez. Barcelona: Salvat Editores.

Jaén, J. (2012) "El lenguaje universal de comunicación en Internet. El lenguaje de internet: fenómenos, memes, virales..." Recuperado de: http://lenguaje-fenomenos-y-memes.blogspot.com.ar

Maynou, A. (2012) "Memes entre la comunicación y la creatividad. Creando comunidad-Habladurias sobre Community Management y Social Media". Recuperado de: https://albertmaynou. wordpress.com/tag/caracteristicas-del-meme/

Rodríguez Marín, D. (2013) Memecracia. Los virales que nos gobiernan. España: Editores Gestión 2000.

Wordpress (2015) "iQué es un 'meme' (no un 'memo')?" Recuperado de https://comunicarbien.wordpress.com/2015/05/26/quees-un-meme-no-unmemo/. 